\title{
Penentuan Harga Air Tanah untuk Irigasi Berkelanjutan di Kabupaten Jembrana
}

\author{
IDA BAGUS MADE WIRAWAN, I MADE SUDARMA, I WAYAN BUDIASA
}

Program Studi Agribisnis, Fakultas Pertanian, Universitas Udayana

Jalan P.B. Sudirman-Denpasar, 80232

Email: wirawanmade7@gmail.com

sudarmaimade@yahoo.com

\begin{abstract}
Determination of Groundwater Prices for Sustainable Irrigation in Jembrana Regency
\end{abstract}

Subak Babakan Yehkuning is relatively new in obtaining Groundwater Irrigation Network, with the code YKN-127 in 2014. This study aims to determine the cost components and water prices that reflect the value of water use in a sustainable manner. The method used in this research is quantitative calculation. The total water discharge from YKN-127 for three planting seasons in September 2015 until August 2016 consecutively was $83,647.01 \mathrm{~m}^{3}$. This amount was derived from the total life of the pump for 2,733 hours, with a discharge 8.5 liters/second. The commodities cultivated in three planting seasons were rice for two times and secondary crop (corn and soybean). Since the availability of ground water has a limited amount, it is important to note that the amount of water use should be less than the availabilities. The concept of sustainable value in the use of water is consisted of the total cost of supply, opportunity costs, and externalities costs. The results showed that the water price reflecting the sustainable water use value for irrigation at YKN-127 was Rp $3,933.91 / \mathrm{m}^{3}$, which consisted of a full supply cost $65.9 \%\left(\mathrm{Rp} 2,592.42 / \mathrm{m}^{3}\right)$, an opportunity cost $27.9 \%\left(\mathrm{Rp} 1,099.43 / \mathrm{m}^{3}\right)$, and depletion premium $6.2 \%$ ( $\mathrm{Rp}$ $242.06 / \mathrm{m}^{3}$ ). This result is almost three times the operational and maintenance costs that farmers usually pay for $\mathrm{Rp} 1,633.99 / \mathrm{m}^{3}$. This price describes the value that must be paid as an effort to maintain the development of irrigated agriculture sector and ground water resources in order to remain sustainable in Jembrana, Bali Province.

Keywords: groundwater, irrigation, full cost, sustainability, Jembrana

\section{Pendahuluan}

\subsection{Latar Belakang}

Menurut High Level Expert Forum (2009), akan terjadi peningkatan permintaan bahan pangan sekitar 70 persen di tahun 2050. Permintaan ini terjadi sebab jumlah penduduk dunia diproyeksikan meningkat sebesar 9,1 milliar jiwa. Jumlah penduduk Indonesia kini telah mencapai 238,5 juta orang, yang merupakan terbesar keempat di dunia dan diproyeksikan akan terus bertambah hingga mencapai 305,6 juta jiwa di tahun 2035 (Bappenas, 2013). Jumlah penduduk Indonesia yang 
tinggi mewajibkan ketersediaan bahan pangan yang harus diproduksi oleh sektor pertanian. Pengembangan sektor pertanian Indonesia kedepannya menghadapi tantangan yang berat akibat besarnya potensi dan tanggung jawab yang dimilikinya.

Salah satu sumberdaya alam yang sangat penting kelangsungannya bagi sektor pertanian adalah air. Sumberdaya air merupakan sumberdaya yang strategis karena menyangkut hajat hidup orang banyak. Bali sendiri memiliki lembaga khusus yang berperan dalam mengatur penggunaan air dalam kegiatan usahatani yang disebut Subak. Menurut Peraturan Daerah Provinsi Bali Nomor 9 Tahun 2012 menjelaskan bahwa Subak adalah organisasi tradisional dibidang tata guna air di tingkat usaha tani pada masyarakat adat di Bali yang bersifat sosio agraris, religius, ekonomis yang secara historis terus tumbuh dan berkembang.

Subak Babakan Yehkuning adalah subak yang mampu menggambarkan kelangkaan air permukaan untuk irigasi di Kabupaten Jembrana. Hal ini dikarenakan subak ini tergolong baru dalam mendapatkan Jaringan Irigasi Air Tanah (JIAT) perpipaan, yaitu pada tahun 2014 dengan kode YKN-127. Kelebihan sifat irigasi air tanah berupa keandalan dan kelenturannya lebih dibandingkan dengan irigasi permukaan disebabkan karena petani memiliki kemampuan untuk mengatur suplai air ketika diperlukan (Kaul dan Sekhon, 1991). Keadaan ini yang menyebabkan harga air harus diperhitungkan dengan seksama dan terperinci tiap-tiap komponen agar nantinya keandalan dan kelenturan yang dimiliki sistem irigasi air tanah tidak menjadi masalah bagi petani akibat salah penetuan harga.

Tujuan penelitian ini adalah menentukan besarnya komponen biaya pembentuk harga air untuk irigasi berkelanjutan yang bersumber dari sumur bor di Kabupaten Jembrana serta menentukan harga air berdasarkan biaya penuh yang mencermikan harga air berkelanjutan.

\section{Metode Penelitian}

\subsection{Lokasi dan Waktu Penelitian}

Penelitian ini dilakukan di Subak Babakan Yehkuning yang berada di wilayah Kabupaten Jembrana Provinsi Bali. Pemilihan lokasi penelitian dilakukan secara sengaja (purposive) dengan alasan mayoritas anggota subak ini menggunakan sumber air dari sumur bor. Subak Babakan Yehkuning mendapatkan pengadaan JIAT perpipaan dan pompa di tahun 2014 sehingga data yang diperoleh dari subak ini tergolong aktual. Penelitian ini dilakukan pada pertengahan bulan Januari 2017 sampai akhir April 2017. Data yang diambil dan diolah adalah data rencana pola tanam dan pengelolaan irigasi untuk mendukung pola tanam selama satu tahun periode tanam tahun 2015 hingga tahun 2016.

\subsection{Data, Sampel Penelitian, dan Analisis Data}

Data yang dikumpulkan untuk penelitian ini adalah data kuantitatif dan kualitatif. Data kuantitatif adalah data yang berwujud angka, seperti: jam hidup pompa/hari, upah operator yang mengoperasikan pompa, harga air minum PDAM 
Kabupaten Jembrana, besaran debit penggunaan air, dan harga air yang dibayarkan petani. Data kualitatif yang dikumpulkan dalam penelitian ini adalah informasi mengenai kebiasaan bercocok tanam petani dalam satu tahun dan kualitas air tanah yang digunakan untuk irigasi.

Metode yang digunakan dalam pengumpulan data primer di penelitian ini adalah wawancara mendalam informan kunci yang terdiri dari pekaseh, petani senior, operator pompa, Kepala PDAM Kabupaten Jembrana dan Bagian Teknis Kementerian Pekerjaan Umum BWS Bali-Penida Provinsi Bali.

Analisis yang digunakan adalah nilai guna air berkelanjutan yang tercermin dari harga air berkelanjutan. Nilai guna air berkelanjutan adalah identifikasi beberapa biaya secara sistematis yang digunakan sebagai penentuan harga air.

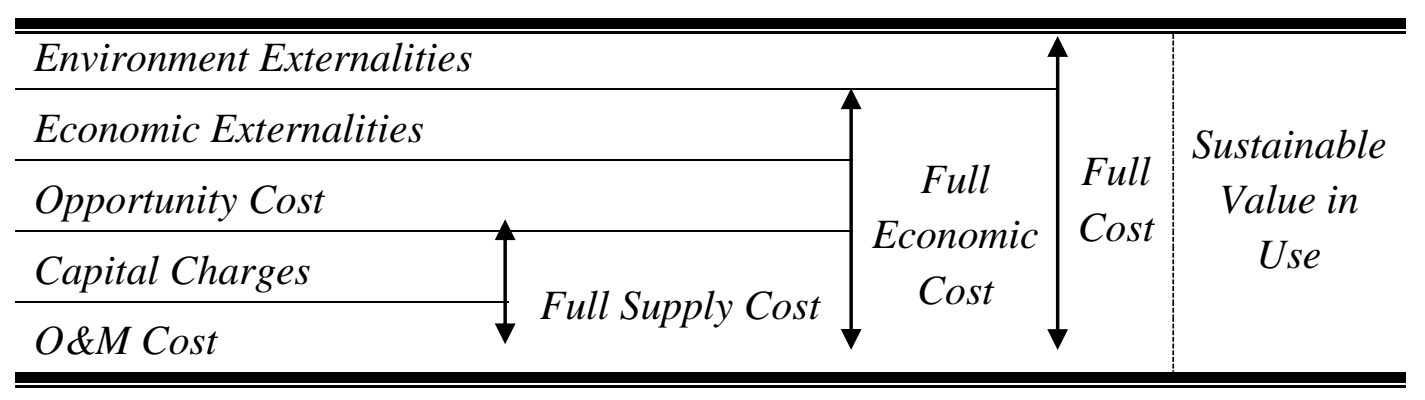

Gambar 1.

Prinsip Umum Biaya Air (Rogers et al., 1998)

Rogers et al. memperkenalkan prinsip umum biaya air sesuai gambar 1. Skema komposisi variasi komponen pembentuk biaya air tersebut diklasifikasikan kedalam tiga tingkat: (1) biaya suplai penuh (The Full Supply Cost), (2) biaya ekonomi penuh (The Full Economy Cost), dan (3) biaya penuh (The Full Cost). Biaya suplai penuh adalah jumlah dari biaya pemeliharaan dan pengoperasian pompa keseharian dengan nilai penyusutan investasi pengadaan sumur pompa. Biaya ekonomi penuh adalah jumlah biaya suplai penuh dengan biaya oportunitas yang berkaitan dengan alternatif pemanfaatan sumberdaya lain, serta biaya eksternalitas ekonomi sebagai nilai pemanfaatan sumberdaya yang terbatas di masa yang akan datang. ADB dalam Budiasa (2011) menjelaskan premi deplesi merupakan instrumen penilaian air yang sesuai dalam analisis ekonomi untuk meningkatkan biaya air dalam kasus penggunaan air yang mengakibatkan cadangan aquifier terkuras. Perhitungan premi deplesi menggunakan perumusan ADB (1998), yaitu premi deplesi $=\left(C_{2}-\right.$ $\left.C_{1}\right) e^{-r(T-t)}$, dan $C_{2}$ adalah biaya per unit air dari sumber air alternatif; $C_{1}$ adalah biaya per unit air dari sumberdaya yang mengalami deplesi; $T$ adalah periode waktu habisnya sumberdaya; $t$ adalah periode waktu yang diperhitungkan dalam analisis; $r$ adalah tingkat bunga $(r=0.12)$; dan $e$ adalah konstanta eksponential $(e=2.7182)$. Menurut perhitungan ini dihasilkan premi deplesi yang akan meningkat ketika cadangan sumberdaya semakin menipis. 
Rogers et al. (1998) menjelaskan bahwa biaya penuh yang mencerminkan nilai guna air berkelanjutan adalah biaya ekonomi penuh yang dijumlahkan dengan nilai dampak lingkungan. Dampak lingkungan yang diakibatkan oleh pemanfaatan sumberdaya air tanah harus diperhitungkan secara terperinci, terutama perlu tidaknya dilakukan treatment lanjutan terhadap kualitas air tanah.

\section{Hasil dan Pembahasan}

\subsection{Komponen Biaya Pembentuk Harga Air untuk Irigasi}

\subsubsection{Biaya operasional dan pemeliharaan (OM cost)}

Biaya operasional adalah biaya keseharian pemanfaatan sistem irigasi, yang termasuk pembelian bahan baku (air mentah), tenaga listrik untuk menggerakkan pompa, tenaga kerja, bahan-bahan untuk perbaikan, dan biaya input untuk mengelola dan menggunakan cadangan, distribusi, biaya perlakuan terhadap kondisi air sadah (Budiasa, 2011). Pompa YKN-127 mengairi 18,3 hektar lahan sawah di Subak Babakan Yehkuning. Subak Babakan Yehkuning menerapkan 3 musim tanam dalam satu tahun. Petani membudidayakan padi pada musim tanam I (September-Desember 2015) dan II (Januari-April 2016), sedangkan pada musim tanam III (Mei-Juli 2016) petani menanam jagung dan kedelai. Pada musim tanam III lahan yang digarap hanya 75\% dari seluruh lahan yang diairi pompa YKN-127 dikarenakan petani harus membayar biaya tinggi untuk mendapatkan air. Total hanya $75 \%$ lahan yang digarap dari keseluruhan 18,3 hektar lahan yang diairi, 10\% untuk jagung dan $90 \%$ untuk kedelai.

Tabel 1.

Total Debit dan Jam Penggunaan Pompa YKN-127 di Subak Babakan Yehkuning

\begin{tabular}{|c|c|c|}
\hline Musim Tanam dan Komoditas & Debit $\left(\mathrm{m}^{3}\right)$ & Waktu (jam) \\
\hline Musim Tanam I (September-Desember, Padi) & $55.998,00$ & 1.830 \\
\hline Musim Tanam II (Januari-April, Padi) & $13.999,50$ & 458 \\
\hline Musim Tanam III (Mei-Agustus, Kedelai dan Jagung) & $13.649,51$ & 446,06 \\
\hline Total & $83.647,01$ & 2.734 \\
\hline
\end{tabular}

Sumber: Data Primer Diolah (2017)

Kebutuhan air untuk tanaman padi pada musim tanam I adalah 1 jam/are dari olah tanah hingga panen. Musim tanam II air diperlukan selama 15 menit/are dari olah tanah hingga panen. Komoditas jagung memerlukan pengairan total selama 15 menit/are hingga panen dan kedelai selama 20 menit/are hingga panen. Keseluruhan penggunaan air dan jam hidup pompa YKN-127 selama tiga musim tanam dapat dilihat pada tabel 1 .

Total debit air tanah yang diperlukan untuk tiga musim tanam adalah 83.647,01 $\mathrm{m}^{3}$. Jumlah ini dipenuhi oleh pompa YKN-127 selama 2.734 jam. Biaya OP dapat dihitung setelah diketahui total jam hidup pompa dan total debit air tanah yang 
digunakan Subak Babakan Yehkuning. Rincian tiap biaya OP dapat dilihat pada tabel 2. Hasil perhitungan biaya OP pompa YKN-127 tertera pada tabel 2.

Tabel 2.

Biaya OP Finansial dan Ekonomis Per Meter Kubik Pompa YKN-127 Tahun 2015/2016

\begin{tabular}{lrr}
\hline Komponen Biaya OP & Biaya Finansial $(\mathrm{Rp})$ & Biaya Ekonomis $(\mathrm{Rp})$ \\
\hline Biaya Tenaga Kerja & $27.335 .625,00$ & $20.160 .023,44$ \\
\hline Biaya Solar & $77.428 .157,81$ & $124.787 .128,13$ \\
\hline Biaya Pemeliharaan & $7.164 .000,00$ & $2.283 .450,00$ \\
\hline Biaya Lainnya & $605.000,00$ & $635.250,00$ \\
\hline Total & $112.532 .782,81$ & $150.865 .851,56$ \\
\hline Biaya OP $\left(\mathrm{Rp} / \mathrm{m}^{3}\right)$ & $1.345,33$ & $1.803,60$ \\
\hline
\end{tabular}

Sumber: Diolah dari Data Primer (2017)

Biaya ekonomis solar diperoleh dengan mengkalikan jumlah solar yang telah digunakan dengan harga solar industri non subsidi meliputi daerah Sumatera, Jawa, Madura, dan Bali dengan harga Rp 8.300,00. Biaya ekonomis tenaga kerja diperoleh dari pengalian biaya finansial tenaga kerja dikalikan dengan faktor konversi. Faktor konversi untuk tenaga kerja yang memelihara jaringan irigasi 75\% diantaranya adalah tenaga kerja tidak terdidik dengan faktor konversi sebesar 0,65. 25\% tenaga kerja lainnya adalah tenaga kerja terdidik dengan faktor konversi sebesar 1, dengan kurs premium diperkirakan 10\% (Gittinger, 1984). Total nilai faktor konversi yang diperoleh untuk tenaga kerja adalah $0,7375\left(C F_{\text {Tenaga Kerja }}=75 \% \times 0,65+\right.$ $25 \% x 1$ ). Faktor konversi standar diatas sering digunakan oleh Bank Pembangunan Asia (Budiasa, 2011). Total keseluruhan biaya ekonomis operasi dan pemeliharaan yang diperoleh adalah sebesar $\mathrm{Rp} 1.803,60 / \mathrm{m}^{3}$.

\subsubsection{Biaya modal (capital charges)}

Biaya modal termasuk konsumsi modal (biaya penyusutan) dan biaya bunga yang diasosiasikan dengan tempat penampungan air seperti waduk atau bendungan, kendaraan pengangkut air dan sistem distribusi. Sesuai dengan hasil wawancara mendalam dengan Bagian Teknis Pekerjaan Umum BWS Bali-Penida Provinsi Bali diperoleh data biaya modal dalam pengadaan JIAT perpompaan di Subak Babakan Yehkuning dalam tabel 3. 
Tabel 3.

Biaya Ekonomi terhadap Modal JIAT Perpipaan YKN-127

\begin{tabular}{|c|c|c|c|c|c|}
\hline No & Kegiatan & $\begin{array}{l}\text { Nilai Finansial } \\
\text { (Rp) }\end{array}$ & $\begin{array}{c}\text { Nilai } \\
\text { Ekonomis } \\
(\mathrm{Rp})\end{array}$ & $\begin{array}{c}\text { Umur } \\
\text { Ekonomis } \\
\text { (Tahun) }\end{array}$ & $\begin{array}{l}\text { Penyusutan } \\
\text { (Rp/Tahun) }\end{array}$ \\
\hline 1. & $\begin{array}{l}\text { Sub Total Pekerjaan } \\
\text { Rumah Pompa }\end{array}$ & 91.511 .196 & 91.511 .196 & 20 & 4.575 .560 \\
\hline 2. & $\begin{array}{l}\text { Sub Total Pekerjaan } \\
\text { Pagar }\end{array}$ & 6.087 .300 & 6.087 .300 & 20 & 304.365 \\
\hline 3. & $\begin{array}{l}\text { Sub Total Pekerjaan } \\
\text { Gorong-Gorong }\end{array}$ & 7.724 .900 & 8.072 .521 & 15 & 538.168 \\
\hline 4. & $\begin{array}{l}\text { Sub Total Pekerjaan } \\
\text { Perpipaan }\end{array}$ & 5.248 .500 & 5.720 .865 & 15 & 381.391 \\
\hline 5 & $\begin{array}{l}\text { Sub Total Pekerjaan } \\
\text { Box Pembagi }\end{array}$ & 15.449 .800 & 16.840 .282 & 15 & 1.122 .685 \\
\hline 6. & $\begin{array}{l}\text { Sub Total Pekerjaan } \\
\text { Sprinkler }\end{array}$ & 40.076 .040 & 43.682 .884 & 15 & 2.912 .192 \\
\hline 7. & $\begin{array}{l}\text { Sub Total Pekerjaan } \\
\text { Autlet/Hydran }\end{array}$ & 114.800 .000 & 125.132 .000 & 15 & 8.342 .133 \\
\hline 8. & $\begin{array}{l}\text { Sub Total Pekerjaan di } \\
\text { Halaman }\end{array}$ & 299.100 & 299.100 & 20 & 14.995 \\
\hline 9. & $\begin{array}{l}\text { Sub Total Pengadaan } \\
\text { Pompa dan Accecories }\end{array}$ & 158.720 .300 & 173.005 .127 & 10 & 17.300 .513 \\
\hline 10. & $\begin{array}{l}\text { Sub Total Pengadaan } \\
\text { Genset dan Accecories }\end{array}$ & 211.749 .000 & 230.806 .410 & 10 & 23.080 .641 \\
\hline 11. & Sub Total Drilling & 169.951 .328 & 185.246 .948 & 25 & 7.409 .878 \\
\hline \multicolumn{2}{|c|}{ Total Investasi } & 821.617 .464 & 886.404 .632 & & 65.982 .481 \\
\hline \multicolumn{2}{|c|}{ Biaya Modal $\left(\mathrm{Rp} / \mathrm{m}^{3}\right)$} & & & & 788,82 \\
\hline
\end{tabular}

Sumber: Dinas Pekerjaan Umum BWS Bali-Penida (2015), diolah.

Seluruh biaya finansial dikonversikan ke dalam biaya ekonomis dengan nilai 1,1 untuk traded component, 0,65 untuk tenaga kerja kasar, dan 1 untuk non-traded component. $80 \%$ biaya pengeboran dan konstruksi jaringan irigasi yang terdiri dari pekerjaan gorong-gorong diasumsikan termasuk traded component. $20 \%$ biaya ekonomis lainnya terdiri dari $10 \%$ non-traded component dan $10 \%$ tenaga kerja kasar. Pembangunan rumah pompa, pekerjaan pagar, dan pekerjaan di halaman dikonversi dari biaya finansial yang terdiri atas $70 \%$ traded component, $20 \%$ tenaga kerja kasar, dan $10 \%$ non-traded component.

Nilai ekonomis dari pengadaan pipa dan kelengkapan lainnya untuk jaringan utama seperti pengadaan pompa dan genset, kegiatan drilling, pekerjaan autlet, sprinkler, dan box pembagi dikonversi dari biaya finansialnya yang 90\% merupakan traded component dan 10\% non-traded component (Budiasa, 2011). Jumlah pengambilan aktual sebesar 8,5 liter/detik pada sumur pompa YKN-127 dan jumlah volume air tanah untuk tiga musim tanam sebesar 83.647,01 $\mathrm{m}^{3}$ di Subak Babakan Yehkuning menyebabkan biaya ekonomi terhadap modal diperhitungkan sebesar Rp $788,82 / \mathrm{m}^{3}$. 


\subsubsection{Biaya oportunitas (opportunity cost)}

Biaya oportunitas dapat diartikan secara sederhana sebagai manfaat yang hilang karena sumber daya yang sama tidak digunakan untuk kegiatan yang terbaik (Budiasa, 2011). Menurut Asian Development Bank (1999) jika pengguna lain menggunakan air untuk kepentingan lain yang lebih mahal, berarti ada biaya oportunitas yang harus dibayarkan akibat kekeliruan dalam alokasi sumber daya air tersebut. Hasil perhitungan biaya oportunitas dapat dilihat pada tabel 4 .

Apabila air tanah digunakan oleh rumah tangga maka diperoleh biaya finansial sebesar Rp 4.502,26/ $\mathrm{m}^{3}$. Angka ini diperoleh dari perkalian biaya beban tiap $10 \mathrm{~m}^{3}$ pertama dan kedua terhadap penggunaan air. Debit penggunaan air tanah untuk tiga musim tanam di Subak Babakan Yehkuning dikurangi $20 \mathrm{~m}^{3}$ untuk dikalikan biaya beban penggunaan air diatas $20 \mathrm{~m}^{3}$ sebesar Rp 4.500,00, sehingga diperoleh biaya total yang harus dibayarkan sebesar Rp 376.600.556 apabila debit air tersebut digunakan bukan untuk usaha pertanian, namun untuk kegiatan rumah tangga.

Tabel 4.

Biaya Oportunitas Penggunaan Air Tanah untuk Irigasi dengan Air Minum Sumur Pompa YKN-127

\begin{tabular}{|c|c|c|c|c|c|}
\hline \multirow[b]{2}{*}{ No } & \multirow[b]{2}{*}{ Klasifikasi } & \multirow[b]{2}{*}{$\begin{array}{l}\text { Pemakaian } \\
\left(\mathrm{m}^{3}\right)\end{array}$} & \multicolumn{3}{|c|}{ Harga Air } \\
\hline & & & $\begin{array}{l}\text { Perpompaan } \\
\text { R1 }\left(\mathrm{Rp} / \mathrm{m}^{3}\right)\end{array}$ & $\begin{array}{c}\text { Biaya } \\
\text { Finansial } \\
(\mathrm{Rp})\end{array}$ & $\begin{array}{c}\text { Biaya } \\
\text { Ekonomis } \\
(\mathrm{Rp})\end{array}$ \\
\hline \multirow{4}{*}{ I } & Kelompok II & & & & \\
\hline & \multirow{3}{*}{ A. Rumah Tangga } & $0-10$ & 24.000 & 240.000 & 196.800 \\
\hline & & $11-20$ & 3.900 & 39.000 & 31.980 \\
\hline & & diatas 20 & 4.500 & 376.321 .556 & 291.312 .068 \\
\hline \multicolumn{3}{|c|}{ Total Harga Air Minum } & & 376.600 .556 & 291.540 .848 \\
\hline \multicolumn{3}{|c|}{ Harga Air Minum (per m3) } & & $4.502,26$ & $3.691,85$ \\
\hline \multicolumn{4}{|c|}{ Opportunity Cost (selisih harga air minum dengan full supply cost) } & & $1.099,43$ \\
\hline
\end{tabular}

Sumber: PDAM Kabupaten Jembrana (2016), diolah.

Biaya ekonomis untuk air minum diperoleh dengan mengalikan biaya finansial dengan faktor konversi. Menurut Budiasa (2011), dengan kontribusi 30\% traded component $(C F=1,1), 60 \%$ unskilled labor $(C F=0,65)$, dan $10 \%$ non-traded component $(C F=1)$ maka nilai ekonomi tarif air minum golongan rumah tangga pada PDAM Kabupaten Jembrana adalah Rp 3.691,85/ $\mathrm{m}^{3}$. Biaya oportunitas sebesar Rp $1.099,43 / \mathrm{m}^{3}$ diperoleh dari perhitungan jumlah biaya operasional dan pemeliharaan, serta biaya modal sebesar Rp 2.592,42 dikurangi total beban tarif air minum untuk rumah tangga.

\subsubsection{Eksternalitas ekonomi (economy externalities)}

Premi deplesi dapat dapat diperkirakan sebagai tambahan biaya pada alternatif penyediaan sumberdaya dari sumber lain (pengganti), misal rainwater storage. Pada 
saat sumberdaya air denga biaya terendah sudah habis, mau tidak mau harus ada harga yang dibayarkan untuk mendapatkan sumberdaya air lainnya dengan harga yang tentunya lebih mahal (Budiasa, 2011).

Harga air tanah pada sumur dangkal adalah $\mathrm{Rp} 10.000,00$ per $\mathrm{m}^{3}$. Periode deplesi untuk sumur dangkal diasumsikan selama 25 tahun. Perhitungan premi deplesi menggunakan rumus dari Asian Development Bank (1998), yaitu $=\left(C_{2}-\right.$ $\left.C_{1}\right) e^{-r(T-t)}$. Harga air yang harus dibayarkan untuk $1 \mathrm{~m}^{3}$ air sumur dangkal yang memiliki harga $\mathrm{Rp} 10.000,00 / \mathrm{m}^{3}$ menghasilkan nilai premi deplesi di tahun pertama melalui perhitungan berikut sebesar Rp $331,59 / \mathrm{m}^{3}$

Pada Subak Babakan Yehkuning diasumsikan bahwa biaya finansial tersebut distribusikan terhadap $10 \%$ traded component $(C F=1,1), 80 \%$ unskilled labor $(C F=0,65)$, dan $10 \%$ peralatan non-traded component $(C F=1)$. Sesuai dengan perhitungan tersebut diperoleh faktor konversi sebesar 0,73 . Faktor konversi ini yang dikalikan dengan biaya finansial sehingga diperoleh biaya ekonomis untuk premi deplesi di tahun pertama sebesar Rp 242,06/ $\mathrm{m}^{3}$.

\subsubsection{Eksternalitas lingkungan (environmental externalities)}

Hasil uji laboratorium menunjukkan bahwa air tanah yang berasal dari pompa YKN-127 layak dikatakan sebagai air bersih dikarenakan tidak ada unsur yang melewati batas maksimum yang diperbolehkan. Dampak lingkungan yang diperhitungkan dalam environmental externalities di Subak Babakan Yehkuning sebesar nol, dikarenakan tidak perlu ada treatment khusus bagi air tanah yang digunakan untuk irigasi. Kualitas air tanah yang diperoleh sudah termasuk dalam golongan air bersih.

\subsection{Penentuan Harga Air Irigasi Berkelanjutan yang Bersumber dari Sumur Bor di Kabupaten Jembrana}

Biaya air tersebut diklasifikasikan kedalam tiga tingkat yang berbeda dan dapat dijelaskan sebagai berikut:

(1) Biaya penuh air ini terdiri dari biaya operasi dan pemeliharaan dan biaya modal. Biaya operasi dan pemeliharaan berkaitan dengan kerutinan pemanfaatan sistem irigasi. Biaya-biaya yang tergolong dalam pengoperasian pompa YKN-127 adalah biaya tenaga kerja, biaya pembelian solar, biaya pemeliharaan dan biaya lainnya. Total biaya ekonomis operasional dan pemeliharaan yang harus dibayarkan oleh petani adalah sebesar Rp $1.803,60 / \mathrm{m}^{3}$. Biaya modal untuk investasi pompa YKN-127 di Subak Babakan Yehkuning terdiri dari 12 komponen. Total biaya modal yang harus dibayarkan untuk mendapatkan air tanah sebanyak satu meter kubik melalui pompa YKN127 adalah Rp 788,82. Biaya suplai penuh (full supply cost) akhirnya dapat diketahui melalui penjumlahan biaya operasional dan pemeliharaan dengan biaya modal dengan jumlah sebesar Rp $2.592,42 / \mathrm{m}^{3}$. 
(2) Biaya ekonomi penuh adalah penjumlahan biaya suplai penuh dengan biaya oportunitas; serta biaya eksternalitas ekonomi sebagai akibat dari kegiatan konsumsi air oleh pihak tertentu. Oportunitas lain pemanfaatan air tanah di Subak Babakan Yehkuning adalah untuk konsumsi rumah tangga. Biaya oportunitas sebesar Rp 1.099,43/ $\mathrm{m}^{3}$ diperoleh dengan memperhitungkan harga air PDAM sesuai Peraturan Bupati Jembrana Nomor 32 Tahun 2016 tentang Penetapan Tarif Air Minum Perusahan Daerah Air Minum Tirta Amertha Jati Kabupaten Jembrana. Perhitungkan eksternalitas ekonomi menggunakan premi deplesi sebagai acuan. Premi deplesi di Subak Babakan Yehkuning memperhitungkan nilai yang harus dibayarkan untuk pemanfaatan sumberdaya air tanah. Sumberdaya air tanah yang dimanfaatkan adalah dari penggunaan sumur dangkal. Hasil yang diperoleh untuk premi deplesi adalah sebesar Rp $242,06 / \mathrm{m}^{3}$. Biaya ekonomi penuh (full economy cost) untuk pompa YKN-127 adalah $\operatorname{Rp} 3.933,91 / \mathrm{m}^{3}$.

(3) Biaya penuh dari aktivitas konsumsi air meliputi biaya ekonomi penuh seperti dijelaskan diatas ditambah dengan biaya pengaruh lingkungan luar (Rogers, 1998). Biaya pengaruh lingkungan luar (environment externalities) mencerminkan nilai kerusakan akibat penggunaan sumberdaya atau sebagai biaya tambahan untuk pengolahan (treatment) air menjadi air tawar. Biaya pengaruh lingkungan untuk air tanah yang digunakan Subak Babakan Yehkuning melalui pompa YKN-127 sebesar Rp 0,- diakibatkan tidak perlunya treatment tambahan untuk kualitas air tanah. Data kualitas air tanah yang diperoleh dari uji laboratorium menunjukkan bahwa tidak ada indikator berbahaya yang melewati ambang batas aman konsumsi. Biaya penuh (full cost) dari tiap satu meter kubik air tanah yang digunakan Subak Babakan Yehkuning melalui pompa YKN-127 adalah Rp 3.933,91.

Sesuai dengan prinsip penentuan harga air oleh Rogers (1998) maka harga air untuk Subak Babakan Yehkuning yang menggunakan sumur pompa YKN-127 dapat dijelaskan dalam gambar 2 .

\begin{tabular}{|c|c|c|c|c|}
\hline \multicolumn{3}{|c|}{ Environment Externalities ( $\mathrm{Rp} 0,-)$} & \multirow{5}{*}{$\begin{array}{l}\text { Full Cost } \\
\text { (Rp3.933, } \\
91)\end{array}$} & \multirow{5}{*}{$\begin{array}{l}\text { Sustain- } \\
\text { able } \\
\text { Value in } \\
\text { Use }\end{array}$} \\
\hline Economic Externalities $(\mathrm{Rp} 2$ & \multirow{4}{*}{$\begin{array}{l}\text { Full Supply } \\
\text { Cost } \\
(\mathrm{Rp} 2.592,42)\end{array}$} & \multirow{4}{*}{$\begin{array}{l}\text { Full } \\
\text { Economic } \\
\text { Cost } \\
\text { (Rp3.933,91) }\end{array}$} & & \\
\hline Opportunity Cost (Rp 1.099, & & & & \\
\hline Capital Charges $(\operatorname{Rp} 788,82)$ & & & & \\
\hline$O \& M$ Cost $(\operatorname{Rp} 1.803,60)$ & & & & \\
\hline
\end{tabular}

Gambar 2.

Penentuan Harga Air Berkelanjutan di Subak Babakan Yehkuning per Meter Kubik

Biaya penuh (full cost) sebesar Rp 3.933,91 dari tiap satu meter kubik air tanah yang digunakan Subak Babakan Yehkuning melalui pompa YKN-127 adalah harga 
air yang sudah menggambarkan nilai guna air secara berkelanjutan (the sustainable value in use of water). Besaran nilai ini sekitar tiga kali lipat biaya operasional dan pemeliharaan ekonomis yang biasanya dibayarkan petani.

Efisiensi irigasi sangat bergantung pula pada penggunaan input pertanian yang cukup. Sekali sistem irigasi dimasukkan dalam sistem usahatani, para petani dapat merencanakan aktivitas pertanian mereka secara tepat untuk mencapai tingkat efisiensi penggunaan lahan yang maksimum (Villachica, 1990). Harga air yang dibayarkan oleh pengguna seharusnya menggambarkan kerelaan membayar atau willingness to pay (WTP) dalam menciptakan kesadaran pengguna terhadap kelangkaan sumberdaya air. Alokasi biaya OP adalah komponen terbesar dalam membentuk harga air. Komponen biaya OP mencakup hampir $45 \%$ dari keseluruhan biaya yang dibayarkan petani. Biaya inilah yang biasanya dibayarkan petani sesuai harga di lapangan.

Konsep WTP atau kesediaan membayar menghasilkan nilai ekonomi yang didefinisikan sebagai pengukuran jumlah maksimum seseorang ingin mengorbankan barang dan jasa untuk memperoleh barang dan jasa lainnya. WTP juga dapat diartikan sebagai jumlah maksimal seseorang mau membayar untuk menghindari terjadinya penurunan terhadap sesuatu (Fauzi, 2006).

\section{Simpulan dan Saran}

\subsection{Simpulan}

1. Besarnya komponen biaya pembentuk harga air untuk irigasi YKN-127 adalah $\mathrm{Rp} 1.803,60 / \mathrm{m}^{3}$ untuk biaya operasional dan pemeliharaan; biaya modal $\mathrm{Rp}$ $788,82 / \mathrm{m}^{3}$; biaya oportunitas $\mathrm{Rp} 1.099,43 / \mathrm{m}^{3}$; dan premi deplesi yang mencerminkan eksternalitas ekonomi dan eksternalitas lingkungan sebesar $\mathrm{Rp}$ $242,06 / \mathrm{m}^{3}$. Komponen biaya OP adalah komponen terbesar pembentuk harga air mencapai $45 \%$ dan biasanya dibayarkan oleh petani. Komponen pembentuk harga air lain, seperti biaya modal, biaya oportunitas, dan biaya eksternalitas disubsidi oleh pemerintah.

2. Harga air yang mencerminkan nilai guna air berkelanjutan untuk irigasi di YKN127 adalah $\mathrm{Rp} 3.933,91 / \mathrm{m}^{3}$, yang terdiri dari biaya suplai penuh sebesar $65,9 \%$ (Rp 2.592,42/ $\mathrm{m}^{3}$ ), biaya oportunitas sebesar 27,9\% $\left(\mathrm{Rp} 1.099,43 / \mathrm{m}^{3}\right)$, dan premi deplesi sebesar $6,2 \%\left(\operatorname{Rp} 242,06 / \mathrm{m}^{3}\right)$. Hasil ini hampir tiga kali lipat biaya operasional dan pemeliharaan yang biasanya dibayarkan petani sebesar $\mathrm{Rp}$ $1.633,99 / \mathrm{m}^{3}$.

\subsection{Saran}

1. Kepada petani di Subak Babakan Yehkuning yang memanfaatkan sumur pompa YKN-127 sebaiknya lebih menghargai sumberdaya air dan memperbaiki manajemen teknis pembagian air agar tidak terjadi konflik dan keberlanjutannya dapat tetap terjaga. 
2. Kepada pemerintah Kabupaten Jembrana sebaiknya mampu memanfaatkan alokasi khusus pendanaan sesuai komponen biaya hasil penelitian ini untuk kegiatan pelestarian sumberdaya air seperti reboisasi harus dapat dilakukan oleh stakeholder secara mandiri agar sumberdaya air dan sektor pertanian Kabupaten Jembrana dapat terus berlanjut hingga di masa mendatang.

3. Kepada kaum akademisi sebaiknya dilakukan penelitian lanjutan mengenai kesediaan membayar air di tingkat petani karena penentuan harga air harus didasarkan konsep willingness to pay atau kesediaan membayar agar memang hasil penelitian ini benar-benar bisa diterapkan dan bermanfaat bagi keberlanjutan sektor pertanian Kabupaten Jembrana.

\section{Ucapan Terimakasih}

Penulis mengucapkan terimakasih kepada: (1) Bapak Nila dan Bapak Agus Winarno dari Dinas PU BWS Bali-Penida yang telah memberikan informasi mengenai JIAT perpipaan, serta (2) Bapak Aji Lauttama selaku pekaseh dari Subak Babakan Yehkuning yang telah memberikan data pola tanam.

\section{Daftar Pustaka}

Asian Development Bank. 1998. The Guidelines for the Economic Analysis of Water Supply Projects. ADB Online.

BAPPENAS. 2013. Jumlah dan Laju Penduduk Indonesia. Proyeksi Penduduk Indonesia 2010-2035, pp-23. Jakarta.

Budiasa, I. W. 2011. Pertanian Berkelanjutan, TEORI DAN PERMODELAN. Udayana University Press. Denpasar.

Dinas Pekerjaan Umum BWS Bali-Penida. 2005. Pembangunan Sumur Produksi untuk Pengembangan Air Tanah. Jakarta: Direktorat Jendral Sumberdaya Air Departemen Pekerjaan Umum Republik Indonesia.

Fauzi, Akhmad. 2006. Ekonomi Sumber Daya Alam dan Lingkungan: Teori dan Aplikasi. PT Gramedia Pustaka Utama. Jakarta.

Gittinger, J. P. 1984. Economic Analysis of Agricultural Project. Economic Development Institute The World Bank.

High Level Expert Forum. 2009. Global Agriculture Towards 2050. How To Feed The World 2050.

Kaul, J.L dan S. Sekhon. 1991. Flexibility and Realibility of Irrigation System and Their Effect on Farming-A Case of Punjab. Ludhiana: Indian Journal of Agricultural Economics, 46 (4): 587-592.

Rogers, P., R. Bhatta, and A. Huber. 1998. Water as Social and Economic Good: How to Put the Pronciple into Practice. Global Water Partnership. Stockholm, Sweden.

Villachica, H. 1990. Sustainable Agricultural System in Humid Tropics of South America. In C. Edwards, Sustainable Agricultural System (pp. 391-437). Soil and Water Concervation Society. 